\section{À margem da segunda escravidão? A dinâmica da escravidão no vale amazônico nos quadros da economia-mundo capitalista}

\author{
Daniel Souza Barroso [1]
}

Luiz Carlos Laurindo Junior [2]
Resumo: Não é incomum, na historiografia brasileira, a percepção da formação econômica e social da Amazônia como espaço no qual uma economia escravista de base agrícola não chegou a se estabelecer. Embora tal noção venha sendo desconstruída por diversos estudos produzidos ao longo das últimas décadas, que evidenciaram a efetividade econômica e demográfica da escravidão negra no vale amazônico, ainda não foi levado a efeito um esforço de reflexão sobre essa questão nos quadros da economia-mundo capitalista, como se apresenta neste artigo. Para tanto, a economia escravista da região é cotejada com a chamada segunda escravidão, faceta mais conhecida da história global da escravidão no século XIX.

Palavras-chave: escravidão no vale amazônico; economia-mundo capitalista; segunda escravidão.

In the margin of second slavery? The dynamic of Amazon Valley slavery in the context of capitalist world-economy

Abstract: It is not unusually in Brazilian historiography the perception of the economic and social formation of the Amazon as a space in which a slave labor and agricultural-based economy hadn't been instituted. Although this idea has been deconstructed by several studies carried out in the last decades, which have demonstrated the economic and demographic effectiveness of slavery in the Amazon Valley, an effort has not yet been made to reflect on the insertion of the region's slave economy in the capitalist world-economy. In this article, we analyze how this insertion occurred in the margin of the most well-known facet of the global history of slavery in the nineteenth century - the second slavery.

Keywords: Amazon Valley slavery; capitalist world-economy; second slavery. 


\section{Introdução}

$\mathrm{N}$ as últimas décadas, diversos estudos ajudaram a superar a noção de inexpressividade demográfica e econômica da escravidão negra no vale amazônico (Salles, 2005; Acevedo Marin, 1985; Sampaio, 2011; Bezerra Neto, 2012). Tais estudos não apenas superaram a ideia reducionista de que a natureza essencialmente extrativista da economia do vale amazônico, com base na força de trabalho indígena, havia dificultado a implantação de uma economia agrícola de base escravista nos antigos estados do Grão-Pará e Maranhão e do Grão-Pará e Rio Negro, como também a ideia de que, com a expansão da borracha como principal produto de exportação da região na segunda metade do século XIX, a agricultura e a presença cativa haviam perdido importância relativa, respectivamente, como atividade econômica e força de trabalho. Novos estudos têm se dedicado a analisar a importância dos escravos em realidades específicas da região, como a economia urbana de Belém (Palha, 2011; Laurindo Jr., 2012) e a economia rural do Baixo Tocantins e da Zona Guajarina (Mota e Barroso, 2017).

Se, por um lado, o conhecimento produzido da economia escrava no vale amazônico ajudou a desconstruir a noção de inexpressividade da escravidão e a avançar na caracterização dos fundamentos internos de produção econômica dessa região, por outro o lugar da escravidão no processo de inserção da economia amazônica nos quadros da economia-mundo capitalista permanece pouco explorado. De modo a adentrarmos essa questão e percebermos a imbricação entre o regional, o nacional e o global, o artigo encontra-se estruturado em três seções: na primeira delas, procedemos à caracterização da dinâmica demográfica da escravidão no Pará — principal reduto escravista da Amazônia nos séculos XVIII e XIX. Na segunda, procedemos à caracterização da economia amazônica no mesmo intervalo. Na terceira e última, examinamos o enquadramento do vale amazônico na economia-mundo capitalista por meio de sua relação com a chamada segunda escravidão.

\section{Demografia da escravidão no Pará oitocentista}

Sem desconsideramos esforços anteriores de introdução de africanos no vale amazônico (Chambouleyron, 2014), foi sob a égide das políticas pombalinas que se assistiu à introdução de um contingente mais expressivo de africanos na região, por meio da Companhia Geral de Comércio do Grão-Pará e Maranhão. Estimativas mais recentes dão conta de que entre 1751 e 1787 — período que cobre o monopólio da Companhia de Comércio (1755-1778), além de anos anteriores e posteriores - ingressaram 22.481 cativos no Grão-Pará e no Rio Negro, a maioria deles se estabelecendo no Pará. Já entre 1788 e 1815, estima-se que 17.072 escravos ingressaram nessas regiões, nos mesmos termos explicitados anteriormente (Hawthorne, 2010, p. 52-53). Com a chegada do Oitocentos, o ritmo de crescimento da população do Pará passou a depender mais do segmento livre, diferentemente do Maranhão, que recebeu um número superior de cativos - 22.414 entre 1751 e 1787 e outros 56.322 entre 1788 e 1815 (Hawthorne, 2010, p. 52-53) - e onde o ritmo de crescimento da população permaneceu mais atrelado ao segmento escravo (Tabela l). 
Tabela 1

População livre e escrava do Pará, do Rio Negro e do Maranhão (1774-1823) e suas respectivas taxas médias geométricas de crescimento anual (TCA)

\begin{tabular}{|c|c|c|c|c|c|c|c|c|c|}
\hline & Ang & & Livres & & & cravo & & Total & TCA \\
\hline & सा० & $\mathrm{N}$ & $\%$ & TCA & $\mathrm{N}$ & $\%$ & TCA & IOtal & Geral \\
\hline$\widetilde{\underline{L}}$ & 1774 & 42.578 & 78,2 & - & 11.886 & 21,8 & - & $54.464(100,0 \%)$ & - \\
\hline$\frac{0}{1}$ & 1797 & 51.018 & 72,3 & $+0,79$ & 19.586 & 27,7 & $+2,20$ & $70.604(100,0 \%)$ & $+1,13$ \\
\hline$\frac{\pi}{0}$ & 1823 & 101.996 & 77,9 & $+2,70$ & 29.015 & 22,1 & $+1,52$ & $131.011(100,0 \%)$ & $+2,41$ \\
\hline & 1774 & 10.604 & 97,9 & - & 222 & 2,1 & - & $10.826(100,0 \%)$ & - \\
\hline$\frac{0}{2} \stackrel{\overline{0}}{\frac{1}{\alpha}}$ & 1797 & 13.790 & 95,6 & $+1,15$ & 636 & 4,4 & $+4,68$ & $14.426(100,0 \%)$ & $+1,26$ \\
\hline & 1823 & 18.219 & 95,0 & $+1,08$ & 962 & 5,0 & $+1,60$ & $19.181(100,0 \%)$ & $+1,10$ \\
\hline$\stackrel{0}{\mathbb{T}}$ & 1774 & 28.702 & 62,9 & - & 16.958 & 37,1 & - & $45.660(100,0 \%)$ & - \\
\hline ๘ొ & 1798 & 41.987 & 53,2 & $+1,60$ & 36.873 & 46,8 & $+3,29$ & $78.860(100,0 \%)$ & $+2,30$ \\
\hline$\sum^{\pi}$ & 1821 & 68.100 & 44,6 & $+2,12$ & 84.534 & 55,4 & $+3,67$ & $152.634(100,0 \%)$ & $+2,91$ \\
\hline
\end{tabular}

Fonte: 1774-1821: Mello (2015, p. 238); 1823: Baena (2004 [1839], p. 260-348).

Em 1823, a população escrava do Grão-Pará e do Rio Negro atingiu o patamar de cerca de 30 mil escravos, que viria a se manter pouco alterado até pelo menos a década de 1870 (Tabela 2) apesar da Cabanagem entre 1835 e 1840; dos desmembramentos da então comarca do Rio Negro, na província do Amazonas, em 1850, e da região compreendida entre os rios Gurupi e Turiaçu, que passou a integrar o Maranhão em 1852 (Souza, 2012, p. 62); da proibição definitiva do tráfico atlântico de escravos sob a Lei Eusébio de Queirós (1850); e de outros fatores, como as manumissões, as fugas de escravos e os surtos epidêmicos que acometeram o Pará oitocentista e que podem ter aumentado a já elevada mortalidade dos cativos. O patamar alcançado no início dos anos 1820 pela escravaria paraense apenas viria a decrescer depois da década de 1870 com a crise da escravidão no Brasil e o avanço da legislação emancipacionista, principalmente a Lei Rio Branco, que tirou o efeito da reprodução endógena como fonte de novos escravos para a província.

Nas décadas de 1870 e 1880, houve redução efetiva no contingente cativo do Pará. Em 1885, pouco antes da Abolição, havia 20.218 cativos no Pará (Araripe, 1886, p. 10), diminuição de praticamente um terço em comparação aos 27.458 cativos existentes em 1872 (Brasil, 1876, p. 212). Em dezembro de 1887, quase às vésperas da Abolição, a população cativa do Pará totalizava, segundo o então vice-presidente da província, Francisco José Cardoso Júnior, 9.902 cativos estimativa, todavia, subestimada, pois não contemplava os escravos pertencentes a algumas localidades que reuniam um grande número de cativos, a exemplo do Acará, situado no Baixo Tocantins (Pará, 1888, p. 17). 
Tabela 2

População livre e escrava do Pará e suas respectivas taxas médias geométricas de crescimento anual (TCA) - exceto Rio Negro/Amazonas

\begin{tabular}{|c|c|c|c|c|c|c|c|c|}
\hline \multirow{2}{*}{ Ano } & \multicolumn{3}{|c|}{ Livres } & \multicolumn{3}{|c|}{ Escravos } & \multirow{2}{*}{ Total } & \multirow{2}{*}{$\begin{array}{l}\text { TCA } \\
\text { Geral }\end{array}$} \\
\hline & $\mathrm{N}$ & $\%$ & $\mathrm{TCA}$ & $\mathrm{N}$ & $\%$ & $\mathrm{TCA}$ & & \\
\hline 1774 & 42.578 & 78,2 & - & 11.886 & 21,8 & - & $54.464(100,0 \%)$ & - \\
\hline 1797 & 51.018 & 72,3 & $+0,79$ & 19.586 & 27,7 & $+2,20$ & $70.604(100,0 \%)$ & $+1,13$ \\
\hline 1823 & 101.996 & 77,9 & $+2,70$ & 29.015 & 22,1 & $+1,52$ & $131.011(100,0 \%)$ & $+2,41$ \\
\hline 1848 & 127.069 & 81,1 & $+0,88$ & 29.706 & 18,9 & $+0,09$ & $156.775(100,0 \%)$ & $+0,72$ \\
\hline 1872 & 247.779 & 90,0 & $+2,82$ & 27.458 & 10,0 & $-0,33$ & $275.237(100,0 \%)$ & $+2,37$ \\
\hline
\end{tabular}

Fonte: 1774-1797: Mello (2015, p. 238); 1823: Baena (2004 [1839], p. 260-348); 1848: Pará (1862, p. 96); 1872: Brasil (1876, p. 211-212).

Se no período de 1774 a 1823 a população escrava do Grão-Pará (exceto o Rio Negro) cresceu à taxa média de 1,84\% a.a., nos intervalos de 1823-1848, 1848-1872 e 1823-1872, as taxas médias de crescimento anual foram de, respectivamente, $0,09 \%,-0,33 \%$ e $-0,11 \%$ (Tabela 2). Apesar da tendência levemente declinante traçada pela população cativa do Grão-Pará ao longo da segunda metade do século XIX, as taxas médias de crescimento de sua escravaria podem ser consideradas "estáveis", no sentido de não variarem significativamente nem para cima nem para baixo em um espaço temporal nada desprezível. Não podemos perder de vista que a população cativa do Pará sofreu baixas por conta dos fatores anteriormente referidos, que em diferentes medidas contribuíram para a redução das taxas de crescimento da escravaria da província, sem com isso necessariamente comprometer a natureza "estável" de seu ritmo de crescimento.

Essa característica destoou do ritmo de crescimento das escravarias de diferentes regiões brasileiras e do país como um todo, basicamente dependentes do tráfico, em distintos pontos do século XIX. A população cativa de São Paulo, por exemplo, cresceu à taxa média anual de 1,75\% entre 1836 e 1872 - período que engloba alguma atividade do tráfico atlântico e a consolidação do tráfico interno (Cunha, 2009, p. 78). Diferentemente do crescimento positivo exibido pela escravaria paulista, a brasileira apresentou crescimento negativo após a Lei Eusébio de Queirós, à taxa de $-1,37 \%$ a.a. entre 1850 e 1872 (Salles, 1996, p. 146). Tanto o exemplo paulista como o brasileiro são relevadores de uma dinâmica demográfica da escravidão umbilicalmente relacionada com o tráfico, elemento que foi responsável pela ampliação da escravaria de São Paulo, mas que no Brasil, uma vez desarticulado e de modo geral, levou ao declínio da população escrava após a Lei Eusébio de Queirós (sobre a historiografia acerca do tráfico interno, ver Motta, 2012a).

Embora importante fornecedor de novos escravos ao Pará até as primeiras décadas do século XIX, por meio de rotas transatlânticas, o fator tráfico não significou a drenagem de escravos da província em direção às províncias cafeicultoras na segunda metade do século XIX. Como evidencia a 
Tabela 3, ao longo das décadas de 1870 e 1880, ao contrário de grande parte das províncias situadas nos atuais Norte e Nordeste do Brasil, o Pará (assim como Pernambuco) não perdeu escravos por meio do tráfico interprovincial. Pelo contrário, entre 1873 e 1885 houve um acréscimo de 475 novos cativos na província por meio do tráfico interno, ainda que esse quantitativo estivesse longe de possibilitar uma renovação ou ampliação efetiva da população escrava do Pará no contexto analisado. ${ }^{3}$

Tabela 3

Estimativas do tráfico interprovincial de escravos (províncias do Norte e do Nordeste, 1873-1885)

\begin{tabular}{cccc}
\hline Província & $\begin{array}{c}\text { Escravos que } \\
\text { entraram }\end{array}$ & $\begin{array}{c}\text { Escravos que } \\
\text { saíram }\end{array}$ & $\begin{array}{c}\text { Saldo } \\
\text { (entradas - saídas) }\end{array}$ \\
\hline Amazonas & - & - & - \\
Grão-Pará & 5.502 & 5.027 & +475 \\
Maranhão & 6.638 & 10.565 & -3.927 \\
Piauí & 2.477 & 5.925 & -3.448 \\
Ceará & - & 7.775 & -7.775 \\
Rio Grande do Norte & 2.520 & 6.563 & -4.043 \\
Paraíba & 509 & 4.324 & -3.815 \\
Pernambuco & 21.132 & 19.360 & +1.772 \\
Alagoas & 7.284 & 11.406 & -4.122 \\
Sergipe & 8.654 & 12.759 & -4.105 \\
Bahia & 14.766 & 23.170 & -8.404 \\
\hline Total & 69.482 & 106.874 & -21.842 \\
\hline
\end{tabular}

OBS: Os dados referentes às saídas dos escravos foram ajustados pelo autor adiante referido por existir uma diferença de 9,44\% entre os números de entradas e os de saídas, em desfavor destas. De maneira a corrigir tal distorção, o autor multiplicou os números de saídas de todas as províncias contempladas pelo fator 1,0944.

Fonte: Slenes (1976, p. 610).

Se, por um lado, a retenção de cativos no Pará no contexto de intensificação do tráfico interprovincial (décadas de 1870 e 1880) esteve em grande medida relacionada com o dinamismo exibido pela economia provincial nesse período (retomaremos essa discussão na seção seguinte), por outro estudos recentes têm demonstrado que a manutenção dos escravos do Pará ao longo de grande parte do século XIX esteve associada à elevada capacidade de reprodução endógena de sua escravaria (Barroso, 2017). Embora essa reprodução possa não ter sido capaz de promover um efetivo

\footnotetext{
${ }^{3}$ Na percepção de José Maia Bezerra Neto (2012, p. 85), durante os anos 1870 e 1880, "à medida que diversas províncias, particularmente as cafeicultoras, adotavam medidas restritivas ao tráfico interno, taxando pesadamente os escravos ingressos nas mesmas, o Grão-Pará tornava-se cada vez mais um mercado bastante promissor aos traficantes de escravos, tanto em face da ausência de leis provinciais restritivas à entrada de escravos na província paraense, somente aprovadas em 1883, quanto em razão dos bons preços obtidos pelos cativos no mercado de Belém”. Quanto às legislações imperial e provincial, baixadas em torno do tráfico interprovincial de escravos, ver Motta (2012b).
} 
crescimento vegetativo da população escrava da província, a exemplo do que já foi evidenciado para Minas Gerais (Martins, 1982; Libby e Paiva, 1995), ${ }^{4}$ as taxas de fecundidade das escravas das principais regiões escravistas do Pará (Belém, Baixo Tocantins e Zona Guajarina) se mostraram semelhantes às das cativas do Sul dos Estados Unidos (Barroso, 2017), maior exemplo existente na historiografia de realidade em que a reprodução endógena atuou como elemento determinante na dinâmica demográfica da escravidão (Klein, 2004).

A elevada mortalidade dos escravos, as manumissões, as fugas e, sobretudo, a Lei Rio Branco parecem-nos ter sido os elementos determinantes a acarretar a redução do contingente cativo do Pará nas décadas de 1870 e 1880; os três primeiros, por implicarem a perda de escravos, e o quarto, por impedir a reposição dos cativos falecidos ou libertados no cômputo geral da população cativa. À exceção da mortalidade, todos esses fatores se conectam à crise da segunda escravidão, questão abordada na última parte do artigo, que levou à derrocada da escravidão nas Américas. No caso do Pará, não dispomos de dados sobre a mortalidade cativa e dispomos de dados apenas parciais sobre as manumissões, que dão conta de que 7.945 cativos foram alforriados entre 1871 e 1885 (Bezerra Neto, 2012, p. 221), número próximo ao quantitativo de escravos subtraídos (9.488) entre 1872 e 1885. Os dados sobre o volume de ingênuos (filhos de mulheres escravas nascidos em condição livre após a Lei Rio Branco) são reveladores do que vimos assinalando: a capacidade de reprodução endógena da escravaria paraense.

\section{Gráfico 1}

População escrava do Pará (1774-1885) - exceto Rio Negro/Amazonas

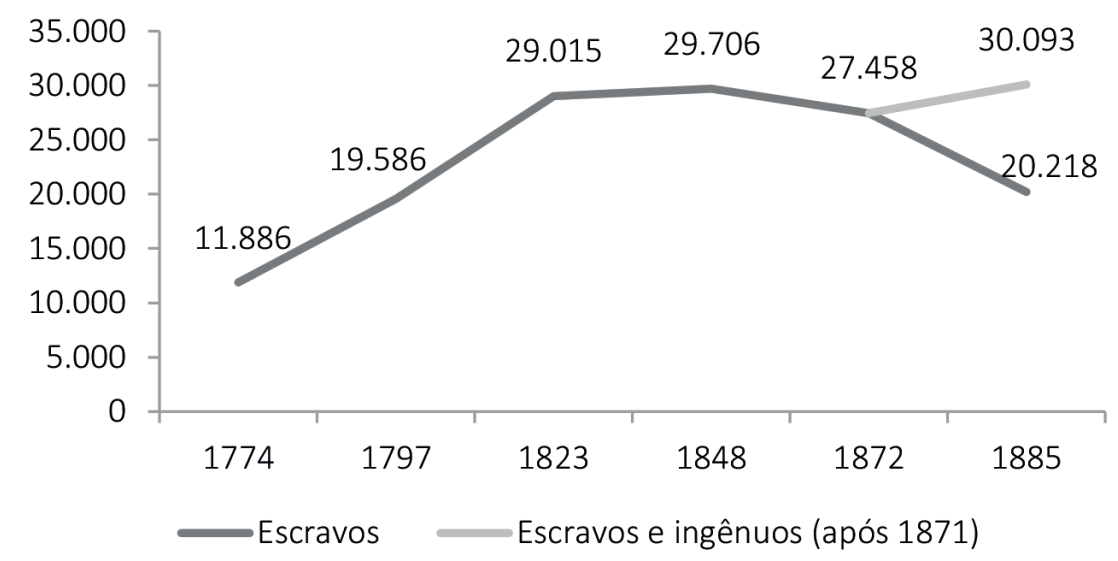

Fonte: 1774/1797: Mello (2015, p. 238); 1823: Baena (2004 [1939], p. 260-284); 1848: Pará (1862, p. 96); 1872: Brasil (1876, p. 211-212); 1885 (tanto para os escravos quanto para os ingênuos): Araripe (1886, p. 9-12).

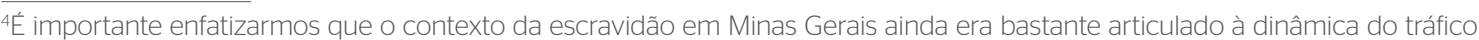
(seja atlântico, interprovincial ou intraprovincial), o que não permitiu às análises dedicadas a Minas Gerais "isolar" o efeito do crescimento natural (Martins, 1983, p. 187). 
O Gráfico l permite-nos observar que o número de ingênuos nascidos entre 1872 e 1885 (10.865) foi superior ao de escravos subtraídos da escravaria paraense no mesmo intervalo (9.488). Não nos cabe conjecturar o que poderia ter acontecido com a população escrava do Pará caso a Lei Rio Branco não tivesse sido baixada em 1871. Cabe-nos, sim, salientar a importância da reprodução endógena (até 1871) como força motriz da dinâmica demográfica dos cativos no Pará oitocentista, que, somada à retenção de cativos na balança do tráfico interprovincial e à redistribuição destes por meio do tráfico intraprovincial, foi um elemento fundamental para a manutenção do contingente escravo da província.

\section{Configurações de uma economia escravista}

Das últimas décadas do século XVII aos meados do século XIX, o cacau figurou como um dos principais produtos de exportação do Pará (Alden, 1976). A produção do gênero, realizada inicialmente pela extração de sua forma nativa (o cacau "bravo") e, mais à frente, a partir do cultivo do chamado cacau "manso", foi incentivada pela Coroa portuguesa desde pelo menos os anos 1670, quando seu potencial de comercialização já estava comprovado. Tratava-se, na leitura de diversos agentes da administração colonial, de um produto com baixo custo de produção e elevado preço de venda (Chambouleyron, 2014, p. 7). A produção do cacau na Amazônia recebeu grande incremento da década de 1750 em diante, com a criação da Companhia Geral de Comércio do GrãoPará e Maranhão, que promoveu a introdução de um grande contingente de cativos africanos no vale amazônico (Dias, 1962; Silva, 2012).

Os dados coligidos na Tabela 4 evidenciam a importância do cacau na pauta de exportações do Pará dos séculos XVIII e XIX. Entre 1756 e 1777, contexto daquela companhia de comércio monopolista, o cacau representou $61 \%$ do valor total das exportações paraenses. Entre os anos 1796 e 1822, a representatividade do cacau no conjunto total de exportações do Pará foi de 50,3\%. No intervalo compreendido entre 1756 a 1822, os anos 1762 e de 1796 foram aqueles em que o cacau alcançou, respectivamente, seu maior (82,3\%) e seu menor $(30,4 \%)$ peso relativo da pauta de exportações paraense. Em que pesem as variações de ano a ano e a redução da representatividade do cacau nas exportações paraenses no período posterior ao de atuação da Companhia de Comércio, o cacau se constituiu, até praticamente os meados do Oitocentos, no principal produto de exportação do Pará. 
Tabela 4

Peso relativo do cacau no total de exportações do Pará (1756-1867) - valores em Réis (Rs.) para os anos com dados disponíveis

\begin{tabular}{cccc|ccccc}
\hline \multirow{2}{*}{ Ano } & Total & Cacau & $\begin{array}{c}\% \\
\text { (Cacau) }\end{array}$ & Ano & Total & Cacau & $\%$ (Cacau) \\
\hline 1756 & $88: 767 \$ 238$ & $35: 701 \$ 087$ & 40,2 & 1775 & $168: 366 \$ 504$ & $109: 362 \$ 000$ & 65,0 \\
1757 & $71: 484 \$ 583$ & $33: 835 \$ 870$ & 47,3 & 1776 & $156: 244 \$ 734$ & $87: 611 \$ 734$ & 56,1 \\
1758 & $15: 115 \$ 867$ & $7: 642 \$ 110$ & 50,6 & 1777 & $170: 508 \$ 251$ & $103.510 \$ 499$ & 60,7 \\
\cline { 5 - 8 } 1759 & $90: 229 \$ 551$ & $52: 255 \$ 928$ & 57,9 & $1756-1777$ & $2.192: 919 \$ 481$ & $1.337: 868 \$ 609$ & 61,0 \\
\cline { 5 - 8 } 1760 & $140: 200 \$ 288$ & $93: 846 \$ 062$ & 66,9 & 1796 & $330: 464 \$ 055$ & $100: 563 \$ 485$ & 30,4 \\
1761 & $130: 953 \$ 764$ & $72: 118 \$ 000$ & 55,1 & 1797 & $255: 506 \$ 350$ & $155: 996 \$ 400$ & 61,1 \\
1762 & $147: 908 \$ 589$ & $121: 710 \$ 187$ & 82,3 & 1798 & $381: 320 \$ 280$ & $207: 607 \$ 400$ & 54,4 \\
1763 & $77: 476 \$ 613$ & $58: 564 \$ 930$ & 75,6 & 1799 & $565: 110 \$ 863$ & $269: 766 \$ 400$ & 47,7 \\
1764 & $91: 888 \$ 662$ & $49: 023 \$ 234$ & 53,4 & 1800 & $598: 505 \$ 930$ & $305: 234 \$ 400$ & 51,0 \\
1765 & $93: 007 \$ 029$ & $47: 417 \$ 109$ & 51,0 & 1801 & $279: 057 \$ 983$ & $122: 503 \$ 500$ & 43,9 \\
1766 & $90: 704 \$ 472$ & $47: 917 \$ 218$ & 52,8 & 1802 & $417: 128 \$ 689$ & $167: 520 \$ 637$ & 40,2 \\
1767 & $89: 196 \$ 787$ & $43: 811 \$ 243$ & 49,1 & 1804 & $478: 378 \$ 124$ & $188: 574 \$ 875$ & 39,4 \\
1768 & $90: 707 \$ 716$ & $61: 461 \$ 140$ & 67,8 & 1805 & $623: 312 \$ 420$ & $299: 214 \$ 550$ & 48,0 \\
1769 & $4: 073 \$ 508$ & $1: 506 \$ 625$ & 37,0 & 1806 & $752: 709 \$ 741$ & $508: 980 \$ 000$ & 67,6 \\
1770 & $114: 669 \$ 083$ & $76: 874 \$ 921$ & 67,0 & 1822 & $560: 499 \$ 070$ & $310: 586 \$ 160$ & 55,4 \\
\cline { 5 - 8 } 1771 & $103: 527 \$ 773$ & $57: 815 \$ 921$ & 55,8 & $1796-1822$ & $5.241: 993 \$ 505$ & $2.636: 547 \$ 807$ & 50,3 \\
\cline { 5 - 8 } 1772 & $120: 799 \$ 861$ & $81: 543 \$ 421$ & 67,5 & $1861-1862$ & $4.604: 851 \$ 282$ & $1.503: 025 \$ 387$ & 32,6 \\
1773 & $121: 172 \$ 452$ & $88: 177 \$ 218$ & 72,8 & $1866-1867$ & $7.387: 107 \$ 009$ & $1.418: 497 \$ 997$ & 19,2 \\
\hline 1774 & $15: 930 \$ 555$ & $6: 168 \$ 152$ & 38,7 & $1861-1867$ & $11.991: 958 \$ 291$ & $2.921: 523 \$ 384$ & 24,4 \\
\hline
\end{tabular}

OBS: Os valores consideram as exportações pelo porto de Belém, entre 1756 e 1822, com destino a Lisboa, e de 1861 a 1867 ("1861-1862" e "1866-1867" não são biênios, mas anos fiscais), com destino a diversos países.

Fonte: 1756-1777: Dias (1962, p. 373); 1796-1822: Alden (1976, p. 127); 1861-1862: Pará (1862, p. 34-56); 1866-1867: Pará (1867, p. 10-33).

No limiar do século XIX, com o declínio das exportações venezuelanas — até então responsáveis por atender a grande parte da demanda internacional do gênero - , houve um aumento substancial na demanda pelo cacau amazônico. O volume de cacau exportado pelo porto de Belém entre 1810 e 1818 foi, em média anual, 68,8\% superior ao exportado entre 1773 e 1808 (Tabela 5). Em termos absolutos e considerando somente os anos para os quais dispomos dos dados de exportação para ambos os intervalos observados, o volume de cacau exportado entre 1810 e 1818 (1.028.174,5 arrobas) corresponde a 72,3\% do volume exportado entre 1773 e 1808 (1.421.1ll arrobas), e a 42,0\% do volume total exportado do gênero entre 1773 e 1822 (2.449.285,5 arrobas). Além disso, é possível notarmos, igualmente, que a produção do cacau tendeu a se ampliar durante parte do Oitocentos. 
Tabela 5.

Gêneros agroextrativistas exportados pelo Pará (1773-1818/1847-1867) — Gêneros selecionados pelos autores para os anos com dados disponíveis

\begin{tabular}{|c|c|c|c|c|c|c|}
\hline \multirow{2}{*}{ Ano(s) } & \multicolumn{6}{|c|}{ Gênero exportado (em arrobas) } \\
\hline & Cacau & Arroz & Café & Algodão & Açúcar & Borracha \\
\hline 1773 & 58.784 & 935 & 4.273 & - & & - \\
\hline 1774 & 4.112 & 7.163 & 141 & 60 & & - \\
\hline 1775 & 72.908 & 19.480 & 4.468 & 60 & & - \\
\hline 1776 & 58.407 & 27.872 & 5.792 & 879 & & - \\
\hline 1777 & 6.907 & 40.346 & 3.542 & 2.053 & & - \\
\hline 1778 & 60.152 & 29.473 & 6.579 & 3.386 & & - \\
\hline 1779 & 57.884 & 89.236 & 4.513 & 5.155 & & - \\
\hline 1780 & 60.395 & 107.252 & 3.122 & 4.912 & & - \\
\hline 1781 & 40.490 & 96.791 & 2.838 & 8.572 & & - \\
\hline 1782 & - & 114.895 & - & 7.315 & & - \\
\hline 1783 & - & 73.116 & - & 7.188 & & - \\
\hline 1784 & 100.776 & 118.604 & 1.796 & 6.608 & 2.055 & - \\
\hline 1785 & 34.877 & 84.681 & 1.683 & 4.908 & & - \\
\hline 1786 & 84.128 & 83.849 & 1.282 & 3.795 & & - \\
\hline 1787 & - & 136.022 & - & 4.212 & & - \\
\hline 1788 & - & 85.521 & - & 5.718 & & - \\
\hline 1789 & - & 96.140 & - & 4.743 & & - \\
\hline 1794 & 79.721 & 103.503 & 2.811 & 7.832 & & - \\
\hline 1796 & 48.116 & 46.880 & 4.042 & 12.666 & & - \\
\hline 1797 & 120.995 & 90.171 & 3.576 & 7.974 & & - \\
\hline 1798 & 94.367 & 59.618 & 5.019 & 8.341 & & - \\
\hline 1799 & 84.302 & 46.417 & 3.224 & 11.569 & & - \\
\hline 1800 & 127.181 & 90.836 & 4.903 & 15.930 & & - \\
\hline 1801 & 64.475 & 39.172 & 2.562 & 10.931 & - & - \\
\hline 1802 & 145.669 & 65.467 & 4.793 & 14.040 & - & - \\
\hline 1808 & 16.465 & 8.248 & - & 443 & - & - \\
\hline 1810 & $105.213,5$ & 83.994 & 2.498 & 4.449 & - & - \\
\hline 1811 & 65.266 & 98.968 & 4.174 & $3.426,5$ & - & - \\
\hline 1812 & 97.834 & 146.216 & 1.544 & 6.531 & - & - \\
\hline 1813 & 85.533 & $107.766,5$ & - & 3.978 & - & - \\
\hline 1814 & 177.643 & 162.486a & - & 5.141 & - & - \\
\hline
\end{tabular}


Continuação

\begin{tabular}{|c|c|c|c|c|c|c|}
\hline \multirow{2}{*}{ Ano(s) } & \multicolumn{6}{|c|}{ Gênero exportado (em arrobas) } \\
\hline & Cacau & Arroz & Café & Algodão & Açúcar & Borracha \\
\hline 1815 & 145.275 & $162.486 a$ & - & 8.509 & - & - \\
\hline 1816 & 123.827 & $128.351,5$ & 1.074 & 12.205 & - & - \\
\hline 1817 & 125.956 & 219.819 & 4.531 & 221.758 & - & - \\
\hline 1818 & 101.627 & 161.642 & 4.267 & 11.827 & - & - \\
\hline 1836-1852 (média anual) & 164.664 & $105.586 b$ & - & 5.123 & 13.753 & - \\
\hline 1852-1857 (média anual) & 185.027 & 38.652 & - & 2.937 & 6.931 & 136.304 \\
\hline 1857-1862 (média anual) & 242.613 & 31.733 & - & 2.273 & 19.763 & 141.459 \\
\hline 1862-1867 (média anual) & 221.623 & 82.370 & - & 7.256 & 17.415 & 274.986 \\
\hline
\end{tabular}

a Os volumes de arroz exportados em 1814 e 1815 se repetem na fonte original - indicada adiante. Não se trata, portanto, de um erro de tabulação de nossa parte.

'Entre 1836 e 1852, foram exportados, para além de 105.586 arrobas de arroz pilado, 23.716 arrobas de arroz com casca, em média, por ano.

OBS: Os valores consideram o volume de gêneros exportados pelo porto de Belém, entre 1773 e 1818, com destino a Lisboa, e de 1836 a 1867, com destino a diversos países. Os valores de 1836 até 1867 foram calculados como médias aritméticas simples, tendo, como numerador, o volume total exportado de cada gênero, e, como denominador, o número de anos de cada um dos quatro intervalos examinados - na própria fonte original. Os valores de 1773 a 1818 consideram somente o volume exportado em arrobas, desconsiderando as frações em libras.

Fonte: 1773-1818: Barata (1973, p. 293-330); 1836-1852: Pará (1862, p. 34-56); 1852-1867: Pará (1867, p. 10-33).

Os dados reunidos nas Tabelas 4 e 5 são importantes na medida em que nos permitem vislumbrar não somente o volume de cacau exportado e o peso relativo desse gênero no conjunto de exportações do Pará entre o final do século XVIII e os meados do século XIX, como também a participação relativa dos demais gêneros agroextrativistas exportados pelo Pará. Se não há como questionarmos todo o protagonismo do cacau, também não há como limitarmos a economia amazônica a um único gênero, muito menos a uma atividade econômica preponderante (extrativismo), tendo em vista os volumes de exportação de outros gêneros (café, algodão e, especialmente, arroz) e o fato de grande parte do cacau exportado nesse período ter sido cultivada, e não somente coletada. ${ }^{5}$

Parece-nos evidente que o século XVIII assistiu ao reposicionamento da agricultura na economia amazônica. Examinando os valores dos gêneros extrativistas e agrícolas exportados pelo Pará entre 1720 e 1820, Francisco Costa observou que o valor exportado agrícola cresceu em média a

\footnotetext{
5De acordo com Rafael Chambouleyron (2014), as informações disponíveis não nos permitem medir com precisão as quantidades de cacau cultivadas e coletadas. A despeito disso, os esforços empreendidos pela Coroa portuguesa no sentido de promover o cultivo do gênero a partir do fim do século XVII com a concessão de diversas sesmarias que se propunham cultivá-lo nos levam a crer que a produção do cacau "manso" possa ter deslanchado no Setecentos, sobretudo a partir da criação da Companhia de Comércio do Grão-Pará e Maranhão.
} 
5,2\% a.a., e o da produção extrativista, em média a 2.3\% a.a. Segundo o autor, no fim do período colonial, a agricultura representava cerca de 40\% do valor exportado pelo Pará (Costa, 2012, p. 206). ${ }^{6}$ Conforme evidenciam os dados da Tabela 5, o volume de gêneros agrícolas exportados se manteve significativo até pelo menos o fim da década de 1860. Mesmo levando em conta uma crescente demanda interna, podemos observar o crescimento dos volumes exportados anualmente de alguns gêneros agrícolas (cacau, açúcar e algodão) entre os períodos 1836-1852 e 1862-1867. Gêneros como o arroz, por sua vez, apresentaram uma recuperação dos volumes exportados, embora sem superar a média anual de exportação do primeiro período vislumbrado.

Porém, caso cotejemos, especificamente, os períodos 1836-1852 e 1852-1857, notaremos um decréscimo nas médias anuais dos volumes exportados do arroz, na casa de 63,4\%; do algodão, em 42,7\%; e do açúcar - gênero que nunca ocupou um lugar de destaque nas pautas de exportação do Pará sete-oitocentista - em 49,6\%. Nesse intervalo, apenas o cacau apresentou crescimento nos volumes de exportação (na casa de 12,4\%). Mais do que indicar uma suposta recuperação após a Cabanagem, os dados podem ser sugestivos de um crescimento na demanda interna por gêneros de subsistência e abastecimento, em um período — anos 1850 e 1860 - em que a população livre do Pará passou a crescer à taxa média de 2,82\% a.a. (Tabela 2), crescimento esse seguido de uma recuperação dos volumes de exportação que viria a se manifestar, mais claramente, no fim dos anos 1860 .

O aparente aumento dos volumes de gêneros agrícolas exportados do Pará nos meados do século XIX foi um dos principais argumentos utilizados por Luciana Batista para se contrapor à noção de que a atividade gomífera havia retirado "braços" da agricultura, apresentada nos relatórios da administração provincial e compartilhada por autores como Roberto Santos (1980) e Barbara Weinstein (1993) para sustentar a ideia de crise na produção agrícola regional (Batista, 2004, p. 63-65). Tal crítica é bem apresentada, não obstante confira muita ênfase ao crescimento dos volumes de exportação durante as décadas de 1850 e 1860 e pouca ênfase ao fato de que existiu, com efeito, uma queda dos volumes médios de exportação anual de gêneros agrícolas (exceto o cacau, de produção agroextrativista) entre os anos 1830 e de 1840 e o quinquênio 1852-1857 (Tabela 5).

Se, por um lado, os dados da Tabela 5 evidenciam a manutenção da agricultura como um importante setor da economia paraense, contrapondo a noção de crise de produção, por outro não há como desconsiderarmos a expansão da produção da borracha e sua consolidação como o principal produto da pauta de exportações do Pará a partir dos meados do século XIX. De acordo com Barbara Weinstein (1993, p. 90): “em fins da década de 1880, o valor anual das exportações de borracha havia subido $800 \%$ acima da cifra correspondente de 1860, [...] na virada do século [XX], a

\footnotetext{
6Segundo Francisco de Assis Costa, o período de 1778 a 1798, entre o fim das atividades monopolistas da Companhia de Comércio e o ocaso do Diretório dos Índios, foi o que apresentou a maior diferença entre as taxas anuais de crescimento da agricultura (7,1\%) e do extrativismo (1,3\%) durante todo o intervalo examinado pelo autor. Advertimos, entretanto, que Costa parece considerar toda a produção de cacau como extrativista - o que pode ter subestimado o crescimento do valor exportado agrícola e superestimado o extrativista, em sua análise. Ver: Costa (2012, p. 197-219). Sobre o reordenamento dos sistemas agrários (extrativistas, agrícolas e agroextrativistas), no Grão-Pará, no contexto das chamadas políticas pombalinas, ver: Ângelo-Menezes (1998).
} 
borracha se tornara o segundo produto brasileiro, constituindo $24 \%$ da exportação total do país". Como é possível observarmos a partir da Tabela 6, no intervalo de 1855 a 1885, o volume exportado de borracha do vale amazônico (Pará e Amazonas) cresceu à elevada taxa média de 5,92\% a.a.

Tabela 6

Exportações de borracha da Amazônia (1855-1885) — inclusive Amazonas

\begin{tabular}{|c|c|c|c|c|c|}
\hline Ano & $\begin{array}{c}\text { Volume } \\
\text { (em toneladas) }\end{array}$ & $\begin{array}{c}\text { Taxa de } \\
\text { crescimento } \\
\text { anual }\end{array}$ & Ano & $\begin{array}{c}\text { Volume } \\
\text { (em } \\
\text { toneladas) }\end{array}$ & $\begin{array}{c}\text { Taxa de } \\
\text { crescimento } \\
\text { anual }\end{array}$ \\
\hline 1855 & 2.197 & - & 1871 & 6.765 & $+20,76 \%$ \\
\hline 1856 & 1.906 & $-13,25 \%$ & 1872 & 8.218 & $+21,48 \%$ \\
\hline 1857 & 1.809 & $-5,09 \%$ & 1873 & 8.291 & $+0,89 \%$ \\
\hline 1858 & 2.242 & $+23,94 \%$ & 1874 & 7.716 & $-6,94 \%$ \\
\hline 1859 & 2.674 & $+19,27 \%$ & 1875 & 7.730 & $+0,18 \%$ \\
\hline 1860 & 2.672 & $-0,07 \%$ & 1876 & 7.909 & $+2,32 \%$ \\
\hline 1861 & 2.515 & $-5,88 \%$ & 1877 & 9.215 & $+16,51 \%$ \\
\hline 1862 & 3.555 & $+41,35 \%$ & 1878 & 9.229 & $+0,15 \%$ \\
\hline 1863 & 4.034 & $+13,47 \%$ & 1879 & 10.136 & $+9,83 \%$ \\
\hline 1864 & 3.466 & $-14,08 \%$ & 1880 & 9.808 & $-3,24 \%$ \\
\hline 1865 & 3.546 & $+2,31 \%$ & 1881 & 9.124 & $-6,97 \%$ \\
\hline 1866 & 5.434 & $+53,24 \%$ & 1882 & 10.493 & $+15,00 \%$ \\
\hline 1867 & 5.827 & $+7,23 \%$ & 1883 & 11.000 & $+4,83 \%$ \\
\hline 1868 & 5.651 & $-3,02 \%$ & 1884 & 11.158 & $+1,44 \%$ \\
\hline 1869 & 5.876 & $+3,98 \%$ & 1885 & 12.322 & $+10,43 \%$ \\
\hline 1870 & 5.602 & $-4,66 \%$ & Total (1855-1885) & 198.120 & $+5,92 \%$ \\
\hline
\end{tabular}

OBS: As taxas de crescimento anual dos volumes exportados de borracha não constam na fonte adiante referenciada, tendo sido as mesmas, por nós incluídas. Entre 1855 e 1885, foram calculadas taxas de crescimento simples. Para todo o intervalo abrangido ("Total”), foi calculada a taxa média geométrica de crescimento anual, tomando como referência os anos 1855 e 1885. Fonte: Weinstein (1993, p. 72).

Esse incremento dos volumes de exportação da borracha decorreu especialmente do aumento da demanda desse gênero no mercado internacional e foi suportado pela expansão das áreas produtoras de borracha para regiões ainda não exploradas do Pará e do Amazonas. Como elucida Weinstein (1993, p. 71): “enquanto, durante os primeiros anos, apenas uns poucos municípios paraenses [...] haviam respondido pela maior parte da borracha produzida, na década de 1870 a extração havia se espalhado para o Oeste". Sem embargo a essa expansão rumo à recém-criada província do Amazonas, Barbara Weinstein (1993, p. 73) esclarece que "a importância de Belém, 
como centro comercial, em nada diminuiu com a expansão para o Oeste". No Pará, as principais áreas produtoras de borracha eram a chamada "região das ilhas" (no Marajó, onde estavam situadas as localidades de Breves, Anajás, Melgaço e Gurupá) e os vales do Xingu e do Tapajós. Mesmo que as bacias do Tocantins e do Guamá fossem áreas com presença de seringueiras, a produção de borracha nessas regiões era menor em quantidade e de qualidade inferior à produção das demais regiões (Weinstein, 1993, p. 57).

Em que pese o fato de a borracha ter impulsionado o notável dinamismo econômico no Pará, sobretudo a partir da década de 1870 , fica evidente que a agricultura e outras importantes atividades econômicas, assentadas ou não no uso de trabalho cativo, mantiveram sua importância, embora gradualmente perdendo peso relativo na pauta de exportações do Pará. ${ }^{7}$ Estudos, como o já referido de Luciana Batista (2004) e o de Francivaldo Nunes (2011), têm evidenciado tal perspectiva. O estudo de Nunes, em particular, apresenta as ações adotadas pela administração provincial para incentivar a expansão e a modernização da agricultura paraense, como a criação de bancos de créditos específicos, a construção de estradas e ferrovias, a organização de escolas e sociedades agrícolas e o projeto de implantação de engenhos centrais (Nunes, 2011, p. 31). A partir dessas ações, a administração provincial buscava potencializar a produção de gêneros agrícolas no Pará.

A comarca da capital, que, além de Belém, abrangia uma série de localidades rurais, era a principal região produtora de alguns desses gêneros, como a cana-de-açúcar e o arroz. A região do rio Tocantins, que compreendia as localidades remanescentes do Baixo Tocantins, destacava-se como uma das principais regiões produtoras de cacau (Pará, 1867, p. 11), ${ }^{8}$ arroz e gêneros de subsistência e abastecimento, tendo na produção da borracha uma atividade não tão destacada, nos termos em que salientamos anteriormente. Por sua vez, as demais regiões da província produziam gêneros diversos voltados tanto à exportação (cacau, borracha e castanha) quanto à subsistência e ao abastecimento interno - estes, nem sempre citados nos relatórios da administração provincial.

Uma das características da economia do vale amazônico, como se observa, é o entrelaçamento de diferentes tipos de atividades produtivas, voltadas tanto aos mercados regional e nacional quanto à economia-mundo capitalista. Entre 1851 e 1854, foi exportado para o mercado mundial o equivalente a 9.722.831\$200 réis em produtos diversos, e, para o mercado nacional, por navegação de cabotagem, o equivalente a 205.592\$021 réis. Apesar de não apresentar cifras, o presidente da província, Sebastião do Rego Barros, em seu relatório de 1854, faz referência à importância da navegação e do comércio no interior do Pará, de difícil mensuração (Pará, 1854, p. 39). Mais de duas décadas depois, em 1879, o então presidente, José Coelho da Gama e Abreu, também apresenta informações sobre as exportações da província, cobrindo os anos 1875 a 1878, que

\footnotetext{
7Para além da agricultura e do extrativismo, a pecuária foi outra atividade econômica de destaque no Pará oitocentista (Bezerra Neto, 2012)

${ }^{8}$ No relatório apresentado à assembleia provincial do Pará em 15/8/1867, o então presidente da província, Joaquim Raymundo de Lamare, sugeria que Cametá era responsável pela produção de praticamente metade de todo o cacau exportado pela província. Segundo Lamare, o cacau era "o primeiro e mais importante produto da agricultura no Pará, [...] sendo dois terços [...] provenientes de cultura do gênero e o resto quase todo proveniente de produção espontânea [extrativismo]" (Pará, 1867, p. 11).
} 
totalizam aproximadamente 48.921.296\$297 réis para o mercado mundial (com destaque para a Inglaterra, para onde foi exportado o equivalente a mais da metade desse valor, 25.168.827\$478 réis) e 1.763.399\$579 réis para o "Sul do Império" (Pará, 1879).

Essa configuração suscitou a constituição de relações de trabalho variadas, pautadas pelo uso de diferentes e complementares tipos de força de trabalho. Como pondera Dale Tomich, o capitalismo não esteve, no decorrer de sua constituição histórica, associado à apenas um tipo de relação de produção e controle do trabalho, muito menos a uma divisão mundial do trabalho estática e atemporal (Tomich, 2011, p. 32-36). A produção, a distribuição, a troca e o consumo devem ser pensados dentro de um campo conceitual unificado e a "relação mercadoria" como o nexo da "produção e troca material e social" (Tomich, 201l, p. 48-49). Nesse sentido, o trabalho assalariado, a escravidão e outras formas não assalariadas podem ser combinados em configurações sociais e econômicas específicas, em espaços e tempos específicos, e mesmo assim se enquadrarem dentro da totalidade das relações articuladas à economia-mundo capitalista (Tomich, 201l, p. 50-51).

O crescimento da população livre do Pará ao longo do século XIX, observado na Tabela 1 , representa uma questão evidente: a ampliação da força de trabalho livre em termos absolutos e relativos, absorvida em uma gama variada de atividades econômicas, com destaque para a produção da goma elástica, principal atividade econômica da província da segunda metade do século. ${ }^{9} \mathrm{~A}$ força de trabalho escrava também foi absorvida em atividades diversas, destacando-se, nesse caso, seu emprego na produção de cacau e em outras atividades agroextrativistas. Livres ou escravos, os trabalhadores da província se inseriram ou foram inseridos em relações de trabalho diversas a fim de produzirem, quiçá no mesmo espaço produtivo, aquilo que a província, a região, o Império e o mercado mundial demandavam, seja por meio da agricultura, do extrativismo, da pecuária, atuando nos serviços urbanos e/ou rurais, domésticos ou não. Se a província e o vale amazônico como um todo tiveram sua força de trabalho livre ampliada, a escravidão por essas paragens apenas começou a perder força no contexto de crise da instituição escravista, sobretudo na década de 1880 (Bezerra Neto, 2009). Voltamos, enfim, à problemática do início do artigo (a retenção dos escravos no Pará à época do intenso tráfico interprovincial no sentido norte-sul, após a lei de 1850) e buscaremos agora entendê-la por outra perspectiva.

\section{O Pará no contexto da segunda escravidão}

A história atlântica entre os séculos XVI e XVIII, de acordo com análise desenvolvida em Escravidão epolítica: Brasile Cuba, 1790-1850 por Márcia Berbel, Rafael Marquese e Tâmis Parron (2010), pode ser matizada em dois grandes sistemas com formações, características estruturais e ritmos temporais

${ }^{9} \mathrm{~A}$ historiografia ainda não ponderou a dimensão e a proporção do emprego de trabalhadores livres e libertos na economia regional, embora trabalhos importantes já tenham contribuído de alguma forma para a elucidação dessa questão. Ver: Santos (1980), Weinstein (1993), Cancela (2006), Bezerra Neto (2009), Nunes (2011), entre outros. 
distintos, não obstante inseridos em um espaço geográfico único: o sistema atlântico ibérico — encabeçado por Portugal e Espanha — e o sistema atlântico do noroeste europeu — no qual França e Inglaterra davam o tom. A crise geral do colonialismo e da escravidão colonial, na virada do XVIII para o XIX, que resultou no modelamento da chamada escravidão oitocentista ou segunda escravidão, é entendida a partir da relação entre os dois sistemas atlânticos, o ibérico e o do noroeste europeu. A diferença entre essas duas estruturas históricas, ambas pautadas pelo escravismo colonial, estaria na vinculação a diferentes ciclos sistêmicos de acumulação de capital (ciclo genovês e ciclo holandês, respectivamente) ${ }_{1}^{10}$ na forma como as potências ibéricas e as do noroeste europeu organizaram as rotas do tráfico de escravos para abastecer suas colônias (articuladas a partir das próprias colônias, no caso ibérico, e dos portos metropolitanos, no outro caso), no papel da alforria (crucial para a organização da sociedade no primeiro caso e bastante limitado no segundo) e da fundamentação ideológica construída para legitimar a escravidão negra em cada quadro societário (pouco e muito racializada, respectivamente).

As reformas bourbônicas e pombalinas da segunda metade do século XVIII, ainda segundo os autores, fortaleceram o sistema atlântico ibérico e, consequentemente, a importância da escravidão em sua estrutura, ao mesmo tempo que o sistema atlântico do noroeste europeu entrava em crise - em grande parte como desdobramento da Guerra dos Sete Anos - , dando margem à redefinição das práticas políticas relacionadas com a escravidão nessa parte do globo. A Revolução de Saint-Domingue também foi vetor nessa crise, impactando fortemente a escravidão negra nas Américas e reforçando sua divisão entre zonas escravistas e não escravistas. No período de 1790 a 1820, portanto, situa-se o ponto de chegada da escravidão no sistema atlântico do noroeste europeu e o ponto de partida para a montagem, a partir da crise do sistema atlântico ibérico e do processo de independência das colônias ibero-americanas, de uma nova estrutura histórica da escravidão atlântica, concretizada no decorrer século XIX (Berbel, Marquese e Parron, 2010) e vinculada ao ciclo sistêmico britânico de acumulação de capital. Nesse novo cenário escravista, os Estados Unidos continuaram tendo papel de destaque, visto que após a Independência mantiveram e redimensionaram sua base escravista. Essa nova escravidão atlântica foi denominada por Dale Tomich segunda escravidão, pois estaria inserida em outro tempo histórico e estruturalmente interconectada de outra forma ao sistema-mundo capitalista (Tomich, 2011).

Assim, as principais áreas escravistas do século XIX tinham características que definiram um segundo ciclo da escravidão, marcado por seu fortalecimento sistêmico em razão da Revolução Industrial, da decorrente reestruturação da divisão mundial do trabalho e de um tripé produtivo nas Américas, açúcar em Cuba, algodão nos Estados Unidos e café no Brasil, commodities demandadas em larga escala no mercado mundial e produzidas com trabalho escravo (Tomich, 2011).

\footnotetext{
${ }^{10}$ Os autores dialogam com Giovanni Arrighi, que, por sua vez, partindo de Braudel e Marx, identifica "um padrão reiterado do capitalismo histórico como sistema mundial", caracterizado por sucessivos ciclos sistêmicos de acumulação, marcados por continuidades e descontinuidades: o genovês (séculos XV ao XVII), o holandês (fim do século XVI ao XVIII), o britânico (segunda metade do século XVIII ao início do XX) e o norte-americano (fim do século XIX até a presente fase de expansão financeira) (Arrighi, 2013, p. 5-9).
} 
Parafraseando Robin Blackburn (2016, p. 17-18), em comparação com a escravidão colonial, a segunda escravidão foi "um regime escravista mais autônomo, mais duradouro e, em termos de mercado, mais 'produtivo', capaz de suportar a ofensiva da Era das Revoluções e de atender à crescente demanda pelos produtos das plantations".

A segunda escravidão no Brasil foi propiciada pela intensificação do tráfico transatlântico no fim do século XVIII e na primeira metade do século XIX, fator responsável por suprir a demanda brasileira por escravos de origem africana (ampliada em razão da economia do café) mesmo após a lei de 1831, primeira medida antiescravista tomada com o intuito de acabar com o tráfico para o Brasil (sobre as práticas e perspectivas em torno da lei de 1831, ver sobretudo Mamigonian [2009], e Chalhoub [2012]). Após a Lei Eusébio de Queirós, como foi dito na primeira parte do artigo, o tráfico interno entre as províncias foi responsável por ampla redistribuição da força de trabalho escrava existente no Império e pelo atendimento da mesma demanda. Segundo Rafael Marquese e Ricardo Salles (2016, p. 142), "a rápida consolidação de um mercado nacional de escravos [...] funcionou como uma correia de transmissão pela qual as forças globais da segunda escravidão ajudaram a moldar os destinos da escravidão no Brasil". Enquanto o café alavancou a economia brasileira e se tornou o principal produto da pauta de exportações do Império, o açúcar cubano e o algodão estadunidense, ao dominarem o mercado mundial, impactaram diretamente a produção e comercialização dessas commodities no país. Para esses autores, foi justamente a perda de dinamismo econômico das demais regiões brasileiras diante do mercado mundial, de um lado, e o desempenho cafeeiro, do outro, que produziram o tráfico interno e o consequente desequilíbrio demográfico, social e político (Marquese e Salles, 2016). ${ }^{11}$

No vale amazônico, já vimos que a escravidão negra se intensificou entre a segunda metade do século XVIII e as primeiras décadas do XIX, exatamente no contexto das reformas pombalinas e a subsequente crise do sistema atlântico ibérico, quando o escravismo colonial dá lugar à segunda escravidão. Conforme mostramos anteriormente, o contingente de escravos aumentou significativamente até a década de 1820 em todas as capitanias que historicamente compunham o antigo estado do Grão-Pará e Maranhão, em compasso com o aumento da população livre. Cinquenta anos depois, a situação é outra: enquanto o Maranhão (não mais atrelado politicamente ao vale amazônico) perde 9.595 escravos entre 1821 e 1872, no Pará a população escrava mantém certa estabilidade, configurando-se uma perda, entre 1823 e 1872, de apenas 1.557 escravos, muito por causa do desmembramento da região a leste do rio Turiaçu e da capitania de São José do Rio Negro — que, no mesmo intervalo temporal, teve sua população escrava mantida na faixa dos 900 indivíduos - e dos demais fatores já elencados nas seções anteriores (Brasil, 1876). Os dados do tráfico interprovincial coligidos por Robert Slenes e apresentados na primeira seção reforçam essa perspectiva: embora em dimensões distintas, entre 1873 e 1885, o Pará apresenta saldo positivo

\footnotetext{
"Cabe pontuarmos que, na esteira desses desequilíbrios, houve mudanças no relacionamento entre senhores e escravos em virtude do horizonte de expectativas de ambos com relação ao tráfico, da necessidade de afirmação da autoridade e do código paternalista pelos primeiros e das práticas costumeiras de cativeiro que acompanhavam os últimos (Mattos, 2013, p. 159-161).
} 
no tráfico interprovincial de cativos, e o Maranhão, saldo negativo, configurando-se como fonte de abastecimento de força de trabalho escrava para o sudeste cafeeiro (Jacinto, 2015). O que explica essa relativa disparidade entre o Pará e o Maranhão? Por que os escravos do Maranhão não foram vendidos para o Pará, geográfica e historicamente mais próximo?

O caminho explicativo aqui proposto passa pela relação de cada um desses espaços escravistas com a segunda escravidão. O Maranhão foi integrado à lógica da segunda escravidão, fornecendo escravos para um de seus eixos dinâmicos na economia mundial - a produção cafeeira no sudeste do Brasil. Ao mesmo tempo, a economia maranhense foi impactada diretamente por outro eixo da segunda escravidão - a produção de algodão no sul dos Estados Unidos. O Pará, ao longo do século XIX, insere-se nas teias do capitalismo por meio da produção de cacau e, principalmente, borracha. Esse segundo produto propiciou grande dinamização da economia do vale amazônico como um todo (Weinstein, 1993) e foi, direta e indiretamente, responsável pela retenção da força de trabalho escrava no Pará (mesmo no Amazonas, apesar da pequena proporção de escravos em sua população total) e, desse modo, por sua posição excepcional na lógica da segunda escravidão (Laurindo Jr., 2017). Os escravos, na segunda metade do século XIX, continuaram sendo empregados na dinamizada economia provincial, reproduzindo-se e sendo distribuídos internamente segundo as demandas de cada região do Pará, e alocados em uma gama variada de atividades, como na produção de cacau — gênero em larga medida produzido por escravos e de grande importância na pauta de exportações da província, durante a maior parte do século XIX - de outros produtos agroextrativistas ${ }^{12}$ e nos serviços urbanos (Palha, 2011; Bezerra Neto, 2012; Laurindo Jr., 2012; Barroso, 2017).

Além disso, é muito provável que a liquidez econômica e os lucros propiciados pela ampliação da produção-exportação da borracha e da produção-comercialização de outros produtos da região no mercado regional e nacional - a partir de um complexo econômico que se formou em torno da economia gomífera - tenham criado condições favoráveis para a retenção dos cativos entre os escravistas da província, independentemente de variações na composição dos plantéis em diferentes regiões do Grão-Pará. ${ }^{13}$ À guisa de comparação, se o boom da borracha muito provavelmente transformou em bom negócio a não venda dos escravos empregados nas demais atividades econômicas do vale amazônico, a diminuição do preço e do peso do açúcar produzido no nordeste no mercado mundial e a perda de dinamicidade dessa economia resultaram na venda em massa dos

\footnotetext{
${ }^{12 H a ́ ~ e v i d e ̂ n c i a s ~ d o ~ u s o ~ d e ~ t r a b a l h a d o r e s ~ e s c r a v o s ~ n a ~ p r o d u c ̧ a ̃ o ~ d e ~ b o r r a c h a, ~ n o ~ e n t a n t o, ~ a s ~ p o u c a s ~ p e s q u i s a s ~ s o b r e ~ a ~ q u e s t a ̃ o ~}$ realizadas até o momento não nos permitem dimensionar como se configuravam as relações senhor-escravo nesses casos, de que forma os cativos eram inseridos nessa produção, muito menos o peso relativo dos escravos nela empregados em relação ao segmento cativo da população e ao cômputo total dos trabalhadores da borracha. Sobre os usos dos escravos nas diferentes regiões e atividades econômicas paraenses, ver: Salles (2005) e Bezerra Neto (2012).

${ }^{13}$ Em estudo recente, observou-se que algumas das principais regiões escravistas do Grão-Pará apresentaram trajetórias distintas em relação à composição dos plantéis e à concentração da propriedade escrava a partir dos meados do século XIX. Enquanto o núcleo urbano central de Belém assistiu à proliferação de plantéis de menor dimensão, tornando a posse de cativos mais bem distribuída na região, o Baixo Tocantins e a Zona Guajarina apresentaram uma tendência à maior concentração dos cativos nas mãos dos maiores escravistas (Barroso, 2017).
} 
escravos empregados nas atividades não açucareiras voltadas ao mercado interno, subsidiárias ou não da produção de açúcar (Slenes, 2004).

Contudo, se o Pará oitocentista foi uma exceção à segunda escravidão no sentido de não contribuir com o abastecimento de força de trabalho da economia cafeeira por meio do tráfico interprovincial, a crise da segunda escravidão, gestada no processo de concentração de escravos em seus eixos dinâmicos de articulação e na consequente desestabilização política e social, afetou diretamente a escravidão naquela província (Marquese e Salles, 2016, p. 143-144; Laurindo Jr., 2017). Tendo como estopim a desestruturação da escravidão nos Estados Unidos após a Guerra Civil, essa crise se converteu em uma onda de questionamentos e ações contrárias à escravidão no Império do Brasil, seja por parte dos escravos, seja por parte dos setores da sociedade que passaram a se identificar, por razões ideológicas e/ou econômicas, com o discurso abolicionista. As medidas tomadas nas províncias de São Paulo, Rio de Janeiro e Minas Gerais para tentar interditar o tráfico interno de cativos, a diminuição das alforrias e a concentração cada vez maior da posse de escravos - em vista dos altos preços praticados no mercado nacional de escravos - tinham tornado muito difícil o acesso dos escravos à liberdade e o acesso de diferentes estratos da sociedade à força de trabalho escrava, inclusive de senhores de grandes plantéis (Marquese e Salles, 2016). Além disso, as expectativas de futuro da escravidão haviam sido abaladas pela abolição da escravidão em Cuba, pelo surgimento de propostas sólidas de abolição da escravidão e pela profusão da campanha abolicionista no centro político do Império (Slenes, 2004). Todos esses fatores condicionantes do fim da escravidão no Brasil, portanto e naturalmente, também atuaram nas províncias do vale amazônico, levando à derrocada do escravismo no Império como um todo.

\section{Conclusão}

Nosso propósito com este artigo, por fim, não foi avaliar a eficácia e o grau de inserção do vale amazônico no sistema-mundo capitalista ou, em outros termos, a integração de uma "periferia" ao "centro" dinâmico do sistema. Como pontua Javier Sebastián (2009, p. 37), é necessário extrapolar as tipificações ideais e superar o "esquema cognitivo centro-periferia", que deixa "escassa margem para a surpresa" e para a pluralidade de experiências e, no caso de seu estudo específico, para a pluralidade de "transições para a modernidade". Segundo Armitage e Subrahmanyam (2010), mesmo as mudanças políticas da era das revoluções, por exemplo, foram marcadamente heterogêneas pelo mundo. Uma história que se quer global, portanto, não pode engolir as especificidades e dinâmicas locais, muito menos ser pensada como uma via de ação e influência em direção única, no sentido centro-periferia. Uma saída, em parte sugerida por tais autores, talvez seja conceber a articulação do regional e do global em uma lógica de determinação dialética a partir da qual o primeiro não seja simplesmente subordinado ao último, mas em que ambos se envolvam como escalas interdependentes (mesmo que hierarquicamente constituídas). 
A história da escravidão no vale amazônico oitocentista pode ser vista como um campo de interseção entre o global e o local, o sistêmico e o particular. Os processos e as dinâmicas políticas, econômicas e sociais internas e específicas da região, determinantes para a retenção de sua população escrava, estiveram entrelaçados de diferentes formas e por diferentes mecanismos às configurações do capitalismo. Por mais que o Pará, principal espaço escravista do vale amazônico, durante grande parte da segunda metade do século XIX, não tenha se enquadrado à lógica da segunda escravidão e perdido escravos para o sudeste cafeeiro - graças à boa representatividade do cacau e, sobretudo, ao predomínio da borracha na exportação provincial, produto esse demandado em larga escala no mercado mundial, de grande peso na pauta de exportações nacional e responsável pela dinamização da economia regional —, a constituição e a crise da segunda escravidão levaram, respectivamente, à redefinição e ao fim do escravismo em solo paraense, como em todo o Império do Brasil. Nesses termos, a explicação tanto para a continuidade quanto para o fim da escravidão no vale amazônico, durante o longo século XIX, passa pelos quadros da economia-mundo capitalista.

Este artigo é fruto de dois projetos de pesquisa de doutorado desenvolvidos pelos autores nos Programas de Pós-Graduação em História Econômica e em História Social da Universidade de São Paulo (USP), financiados pela

Fundação de Amparo à Pesquisa do Estado de São Paulo (FAPESP, Processo n.21188-5/2012) e pela Coordenação de Aperfeiçoamento de Pessoal de Nivel Superior (CAPES). 


\section{Fontes impressas}

BRASIL. Diretoria Geral de Estatística. Recenseamento geral do Império de 1872. Rio de Janeiro: Typ. Leuzinger/ Tip. Commercial, 1876. v. 1.

PARÁ. Fala que o exmo. sr. conselheiro Sebastião do Rego Barros, presidente desta província, dirigiu à Assembleia Legislativa Provincial, na abertura da mesma Assembleia, no dia 15 de agosto de 1854. Pará: Typ da Aurora Paraense, 1854. p. 39.

Relatório apresentado à Assembleia Legislativa da Província do Pará na primeira sessão da XIII Legislatura pelo exmo. sr. presidente da província dr. Francisco Carlos de Araújo Brusque em Io de setembro de 1862. Pará: Typ. de Frederico Carlos Rhossard, 1862.

\section{Referências bibliográficas}

ACEVEDO MARIN, Rosa Elizabeth. Du travail esclave au travail libre: le Para (Brésil) sous le régime colonial et sous l'Empire (XVII-XIX siècles). Tese (Doutorado em História e Civilizações), École des Hautes Études en Sciences Sociales, Paris, 1985.

ALDEN, Dauril. The significance of cacao production in the Amazon region during the late colonial period: an essay in comparative economic history. Proceedings of the American Philosophical Society, Philadelphia, v. 120, n. 2, p. 103-135, abr. 1976.

ÂNGELO-MENEZES, Maria de Nazaré. Histoire sociale des systèmes agraires de la vallée du Tocantins-état du ParáBrésil: colonisation européenne dans la deuxième moitié du XVIII siècle et la première moitié du XIX siècle. Tese (Doutorado em História e Civilizações), École des Hautes Études en Sciences Sociales, Paris, 1998.

ARARIPE, Tristãode Alencar. Dadosestatísticoseinformações para os imigrantes. Belém: Typ. do Diário de Notícias, 1886.

ARMITAGE, David; SUBRAHMANYAM, Sanjay. Introduction: the age of revolutions, c.1760-1840: global causation, connection, and comparison. In:

(Ed.). The age of revolutions in global context, c. 1760-1840. Londres: Palgrave, 2010.

ARRIGHI, Giovanni. Olongo século XX: dinheiro, podere as origens de nosso tempo. Rio de Janeiro: Contraponto, 2013.
Relatório apresentado à Assembleia Legislativa Provincial por s. ex 0 sr. vice-almirante e conselheiro de Guerra, Joaquim Raymundo de Lamare, presidente da província, em 15 de agosto de 1867. Belém: Typ. de Frederico Carlos Rhossard, 1867.

Fala com que o exmo. sr. doutor José Coelho da Gama e Abreu, presidente da província, abriu a $2^{\underline{a}}$ sessão da $21^{\underline{a}}$ Legislatura da Assembleia Legislativa da Província do GrãoPará, em 16 de junho de 1879. Pará: [s.n.], 1879.

Fala com que o exmo. sr. conselheiro Francisco José Cardoso Júnior, primeiro vice-presidente da província do Pará, abriu a primeira sessão da XXVI Legislatura da Assembleia Provincial, no dia 4 de março de 1888. Belém: Typ. do Diário de Notícias, 1888.

BAENA, Antônio Ladislau Monteiro. Ensaio corográfico sobre a província do Pará. Brasília: Senado Federal/ Conselho Editorial, 2004 [1839].

BARATA, Manoel. A antiga produçãoe exportação do Pará: estudo histórico e econômico. In: (Org.). Formação histórica do Pará. Belém: EDUFPA, 1973. p. 300-330.

BARROSO, Daniel Souza. O cativeiro à sombra: estrutura da posse de cativos e família escrava no Grão-Pará (1810-1888). Tese (Doutorado em História Econômica), Universidade de São Paulo, São Paulo, 2017.

BATISTA, Luciana Marinho. Muito além dos seringais: elites, fortunas e hierarquias no Grão-Pará, c.1850-c.1870. Dissertação (Mestrado em História Social), Universidade Federal do Rio de Janeiro, Rio de Janeiro, 2004.

BERBEL, Márcia; MARQUESE, Rafael; PARRON, Tâmis. Escravidão e política: Brasil e Cuba, 1790-1850. São Paulo: Hucitec/Fapesp, 2010.

BEZERRA NETO, José Maia. Por todos os meios legítimos e legais: as lutas contra a escravidão e os limites da Abolição (Brasil, Grão-Pará: 1850-1888). Tese (Doutorado em História), Pontifícia Universidade Católica de São Paulo, São Paulo, 2009.

Escravidão negra no Grão-Pará (séculos XVII-XIX).

2. ed. Belém: Paka-Tatu, 2012. BLACKBURN, Robin. Por que segunda escravidão?. In: MARQUESE, Rafael; SALLES, Ricardo (Org.). Escravidão e capitalismo histórico 
no século XIX: Cuba, Brasil e Estados Unidos. Rio de Janeiro: Civilização Brasileira, 2016. p. 13-54.

CANCELA, Cristina Donza. Casamento e relações familiares na economia da borracha (Belém, 1870-1920). Tese (Doutorado em História Econômica), Universidade de São Paulo, São Paulo, 2006.

CHALHOUB, Sidney. A força da escravidão: ilegalidade e costume no Brasil oitocentista. São Paulo: Companhia das Letras, 2012.

CHAMBOULEYRON, Rafael. Cacao, bark-clove, and agriculture in the Portuguese Amazon region in the seventeenth and early eighteenth century. Luso-Brazilian Review, Madison, v. 5l, n. 1, p. 1-35, 2014.

COSTA, Francisco de Assis da. A economia colonial do Grão-Pará: uma avaliação crítica (1720-1822). Economia e Sociedade, Campinas, v. 21, n. 44, p. 197-219, abr. 2012.

CUNHA, Maísa Faleiros da. Demografia e família escrava: Franca, SP, século XIX. Tese (Doutorado em Demografia), Universidade Estadual de Campinas, Campinas, 2009.

DIAS, Manuel Nunes. As frotas do cacau da Amazônia (1756-1777). Revista de História, São Paulo, n. 50, p. 363 377, mar./jun. 1962.

HAWTHORNE, Walter. From Africa to Brazil: culture, identity, and an Atlantic slave trade, 1600-1830. Cambridge: Cambridge University Press, 2010.

JACINTO, Cristiane Pinheiro dos Santos. Fazendeiros, negociantes e escravos: dinâmica e funcionamento do tráfico interprovincial de escravos no Maranhão (18461888). In: GALVES, Marcelo Cheche; COSTA, Yuri (Org.). O Maranhão oitocentista. 2. ed. São Luís: Café \& Lápis/Uema, 2015. p. 241-268.

KLEIN, Herbert S. A population history of the United States. Cambridge: Cambridge University Press, 2004.

LAURINDO JR., Luiz Carlos. A cidade de Camilo: escravidão urbana em Belém do Pará (1871-1888). Dissertação (Mestrado em História), Universidade Federal do Pará, Belém, 2012.

Escravidão negra, capitalismo e tráfico interno de escravos no Pará oitocentista: aspectos gerais e o caso de Santarém. Anais do 8o Encontro Escravidão e Liberdade no Brasil Meridional, Porto Alegre, 2017.

LIBBY, Douglas Cole; PAIVA, Clotilde Andrade. Caminhos alternativos: escravidão e reprodução em Minas Gerais no século XIX. Estudos Econômicos, São Paulo, v. 25, n. 2, p. 203-233, maio/ago. 1995.
MAMIGONIAN, Beatriz Gallotti. In the name of freedom: slave trade Abolition, the law and the Brazilian branch of the African emigration scheme (Brazil-British West indies, 1830s-1850s). Slavery \& Abolition, Londres, v. 30, n. 1, p. 41-66, fev. 2009.

MARQUESE, Rafael; SALLES, Ricardo. A escravidão no Brasil oitocentista: história e historiografia. In:

(Org.). Escravidão e capitalismo histórico no século XIX: Cuba, Brasil e Estados Unidos. Rio de Janeiro: Civilização Brasileira, 2016. p. 99-162.

MARTINS, Roberto Borges. Growing in silence: the slave economy of nineteenth-century Minas Gerais, Brazil. Dissertação (Ph.D. em História), Vanderbilt University, Nashville, 1982.

Minas Gerais, século XIX: tráfico e apego à escravidão numa economia não-exportadora. Estudos Econômicos, São Paulo, v. 13, n. 1, p. 181-209, jan./ abr. 1983.

MATTOS, Hebe. Das cores do silêncio: os significados da liberdade no sudeste escravista (Brasil, século XIX). 3. ed. Campinas: Unicamp, 2013.

MELLO, Márcia Eliane de Souza e. Contribuição para uma demografia do estado do Grão-Pará e Maranhão. 1774-1821. Anais de História de Além-Mar, Lisboa, v. 16, p. $227-253,2015$.

MOTA, Antonia da Silva; BARROSO, Daniel Souza. Economia e demografia da escravidão no Maranhão e no Grão-Pará: uma análise comparativa da estrutura da posse de cativos (1785-1850). Revista de História, São Paulo, n. 176, p. 1-41, 2017.

MOTTA, José Flávio. Corpos escravos, vontades livres: posse de cativos e família escrava em Bananal (18011829). São Paulo: Annablume, 1999.

. Escravos daqui, dali e de mais além: o tráfico interno de cativos na expansão cafeeira paulista. São Paulo: Alameda, 2012a.

. A lei, ora a lei! Driblando a legislação do tráfico interno. História e Economia, São Paulo, v. 10, n. 1, p. 15-28, jan./jun. 2012b.

NUNES, Francivaldo Alves. Sob o signo do moderno cultivo: Estado imperial e agricultura na Amazônia. Tese (Doutorado em História Social), Universidade Federal Fluminense, Niterói, 2011.

PALHA, Bárbara da Fonseca. Escravidão negra em Belém: mercado, trabalho e liberdade (1810-1850). Dissertação (Mestrado em História), Universidade Federal do Pará, Belém, 2011. 
SALLES, Ricardo. Nostalgia imperial: escravidão e formação da identidade nacional no Brasil do Segundo Reinado. Rio de Janeiro: TopBooks, 1996.

SALLES, Vicente. O negro no Pará sob o regime da escravidão. 3. ed. Belém: IAP, 2005.

SAMPAIO, Patrícia Melo. Espelhos partidos: etnia, legislação e desigualdade na Colônia. Manaus: Edua, 2011.

SANTOS, Roberto. História econômica da Amazônia (18001920). São Paulo: T. A. Queiroz, 1980.

SEBASTIÁN, Javier Fernández. Hacia una historia atlántica de los conceptos políticos. In: (Dir.).

Diccionario políticoy social del mundo ibero-americano: la era de las revoluciones, 1750-1850. Madri: Fundación Carolina/ Sociedad Estatal de Conmemoraciones Culturales/ Centro de Estudios Políticos y Constitucionales, 2009. p. 25-45.

SILVA, Marley Antônia Silva da. A extinção da Companhia de Comércio e o tráfico de africanos para o estado do Grão-Pará e Rio Negro (1777-1815). Dissertação (Mestrado em História), Universidade Federal do Pará, Belém, 2012.

SLENES, Robert W. The demography and economics of Brazilian slavery, 1850-1888. Dissertação (Ph.D. em História), Stanford University, Palo Alto, 1976.

. The Brazilian internal slave trade, 1850-1888:

regional economics, slave experience, and the politics of a peculiar market. In: JOHNSON, Walter. The chattel principle: internal slave trades in the Americas. New Haven/Londres: Yale University Press, 2004.

SOUZA, Sueny Diana Oliveira de. Um rioe suas gentes: ocupação e conflitos nas margens do rio Turiaçu na fronteira entre Pará e Maranhão (1790-1824). Dissertação(Mestrado em História), Universidade Federal do Pará, Belém, 2012.

TOMICH, Dale W. Pelo prisma da escravidão: trabalho, capital e economia mundo. São Paulo: Edusp, 2011.

WEINSTEIN, Barbara. A borrachana Amazônia: expansãoe decadência (1850-1920). São Paulo: Hucitec/Edusp, 1993. 